\title{
Paleomonsoon modeling within PMIP: Recent progress and future directions
}

\author{
Jian Liu, L. Ning, M. Yan, W. Sun, K. Chen and Y. Qin
}

\begin{abstract}
The recent progress on paleomonsoon modeling on various timescales within the five typical periods included in PMIP4 simulations are summarized in this paper. The remaining controversial issues and potential directions of the paleomonsoon modeling for future studies are also discussed.
\end{abstract}

During recent decades, remarkable progress has been made on monsoon variability and physical mechanisms, both by the modern and paleoclimatic communities (Fig. 1; Wang et al. 2017). However, paleomonsoon variability on different spatiotemporal scales is a complex topic requiring more studies from both proxy reconstructions and numerical modeling simulations. Phase 4 of the Paleoclimate Modelling Intercomparison Project (PMIP4) provides unique opportunities to better understand the past changes and corresponding physical mechanisms of the paleomonsoon on different timescales using updated models, more comprehensive boundary conditions, and improved experimental protocols compared with previous PMIP phases (Kageyama et al. 2018).

\section{Last millennium}

Previous paleomonsoon studies focusing on centennial changes during the last millennium (LM) have mainly compared the monsoon variability during the typical climatic periods within the LM, i.e. the Medieval Climate Anomaly (MCA) and the Little Ice Age (LIA; e.g. Jungclaus et al. 2017). Results indicate stronger (weaker) East Asian summer monsoon (EASM) and Indian summer monsoon during the MCA (LIA) due to the changes in the land-sea thermal contrast and atmospheric circulation, which were induced by total solar irradiance and volcanic eruptions. The coherent responses of monsoon systems to centennial-scale modulation of the total solar irradiance and volcanic eruptions found in both model simulations and proxy reconstructions indicate the robustness of the physical mechanisms behind this variability. However, despite the remarkable progress, it is not easy to quantitatively separate the contributions from external forcings and internal variability (Wang et al. 2017).

On the decadal timescale, monsoon variability is primarily associated with internal variability, e.g. Pacific decadal oscillation and Atlantic multi-decadal oscillation. Meanwhile, external forcings, such as volcanic eruptions, solar radiation, and land-use and land-cover change, could also influence the monsoon variability through regulating the land-sea thermal contrast, cycle of surface water, and energy balance (e.g. Qin et al. 2020). Although transient model simulations cannot exactly match the decadal monsoon phases with those found in the proxy reconstructions because models have their own initial conditions, specific events relevant to external forcings could still be reproduced through design of sensitivity experiments. Moreover, in addition to the experiments with default forcings, further experiments with different combinations of external forcings will focus on either specific periods during $L M$ or the last two millennia in PMIP4. These will contribute to the exploration of the forcing uncertainties and the model-data comparisons on multiscale monsoon variability (Jungclaus et al. 2017).

\section{Mid-Holocene and last interglacial}

The impacts of orbital forcing on paleomonsoon variability are examined through two groups of equilibrium simulations covering two interglacial epochs with greenhouse gas (GHG) levels similar to the pre-industrial (PI) period and the continental configurations almost identical to modern period, i.e. the mid-Holocene (MH), approximately 6 kyr BP, and the last interglacial (LIG; OttoBliesner et al. 2017), approximately $127 \mathrm{kyr}$ BP. In general, the multi-model ensemble mean results show an enhanced Northern Hemisphere monsoon and reduced Southern Hemisphere monsoon, especially for the enhanced North African and Asian monsoons, and a weaker Australian monsoon both during the MH and LIG (Fig. 2; Brierley et al. 2020; Otto-Bliesner et al. 2021). Meanwhile, because of the larger insolation anomalies during the LIG compared to $\mathrm{MH}$ simulations, the changes of individual monsoon systems (e.g. areal extents and total amount of precipitation) during the LIG have a greater magnitude than those in the $\mathrm{MH}$ (Fig. 2)

$$
y r s \quad 10^{0} 10^{1} 10^{2} 10^{3} 10^{4} 10^{5} 10^{6} 10^{7} 10^{8}
$$

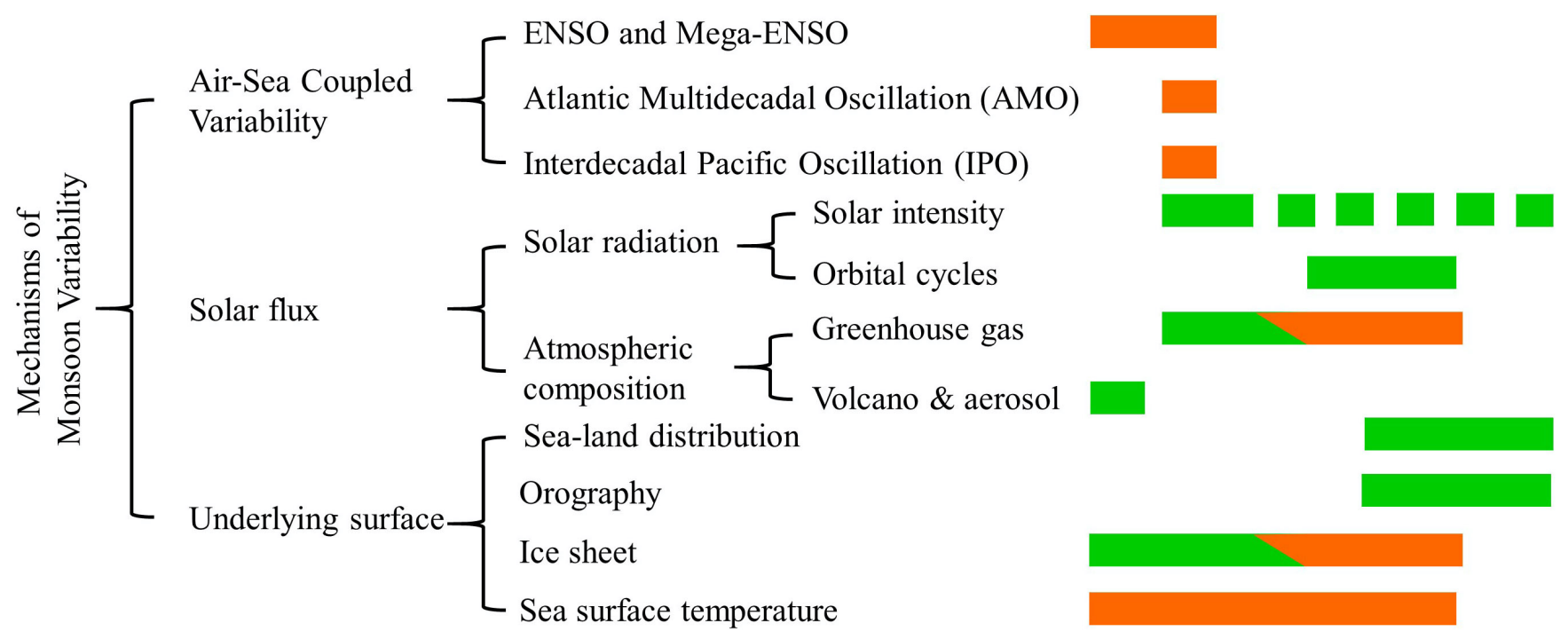


(a) Areal extent

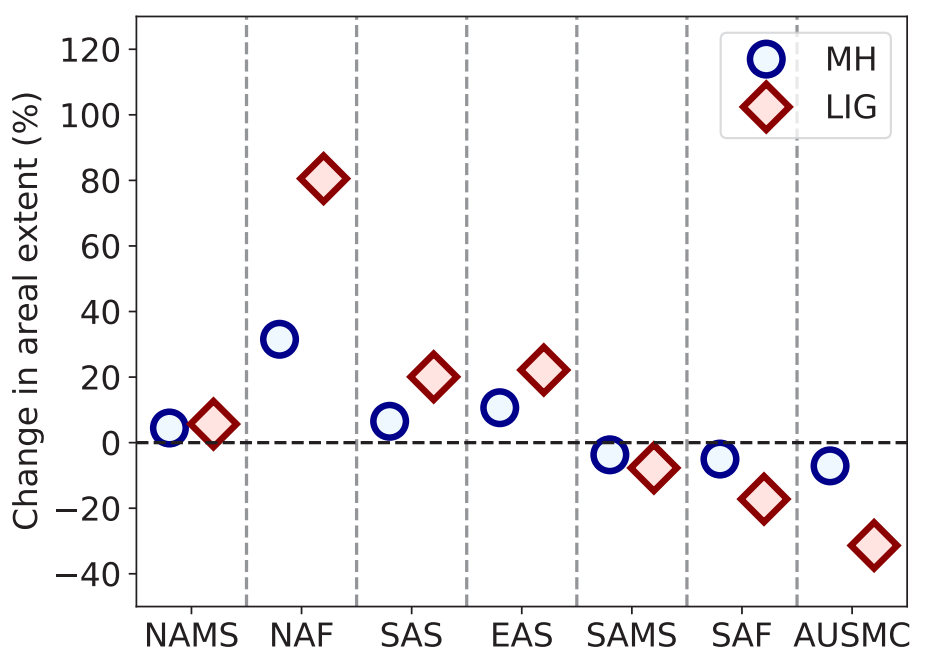

(b) Total amount of precipitation

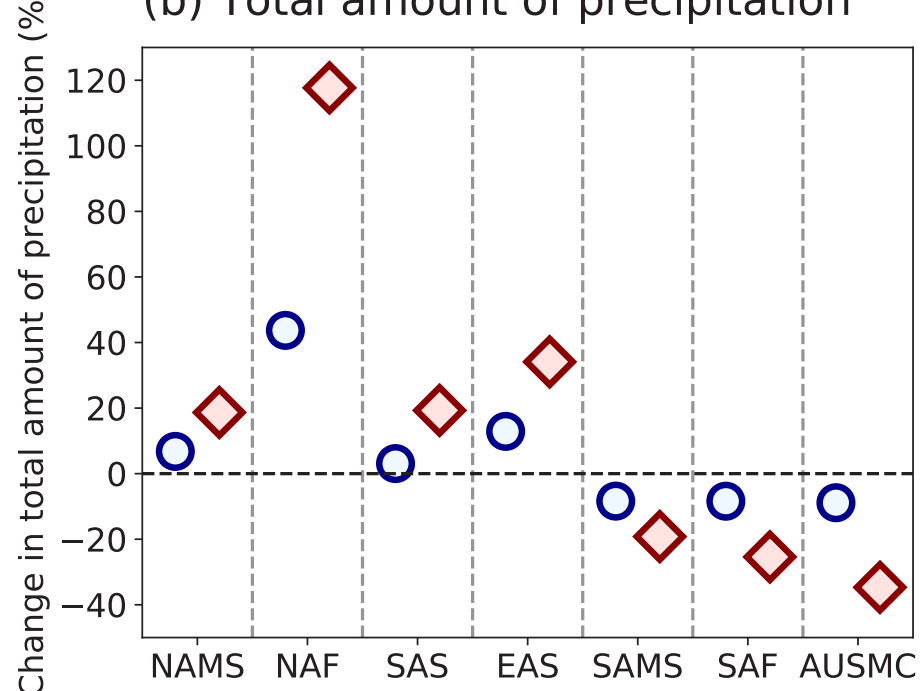

Figure 2: Multi-model ensemble mean of (A) relative changes of areal extents and (B) relative changes in total amount of precipitation in individual monsoons from PMIP4 MH and LIG simulations. The abbreviations used to identify each regional monsoon are as follows: North America monsoon system (NAMS), North Africa (NAF), South Asia (SAS), and East Asia summer (EAS) monsoon in the Northern Hemisphere and South American Monsoon System (SAMS), southern Africa (SAF), and Australian-maritime continent (AUSMC) monsoon in the Southern Hemisphere (adapted by Anni Zhao from Fig. 7 from Brierley et al. 2020 and Fig. 16 from Otto-Bliesner et al. 2021).

In addition to the aforementioned equilibrium simulations, several groups of transient simulations covering the entire Holocene have been carried out (e.g. Braconnot et al. 2019; Bader et al. 2020). These provide opportunities to investigate the characteristics and mechanisms behind multi-scale monsoon variability during the Holocene. These studies have suggested that the interannual- to millennial-scale monsoon variability could be influenced by internal variability, e.g. El Niño-like SST modes, Indian Ocean Dipole (IOD)-like SST modes, the AMOC, and external forcings, e.g. orbital parameters and GHGs (Braconnot et al. 2019; Crétat et al. 2020; Bader et al. 2020). For example, Braconnot et al. (2019) and Crétat et al. (2020) found that changes in orbital parameters cause long-term drying trends in the Indian and West African monsoons, but the Indian monsoon is more sensitive to anthropogenic GHGs, while ENSO and the IOD modulate the interannual-to-decadal Indian monsoon variability. Moreover, some extreme droughts that have been strongly associated with monsoon weakening, e.g. the $4.2 \mathrm{kyr}$ BP event, may have been caused by both long-term drying trends (due to orbital forcing) and low-frequency fluctuations (due to internal variability).

\section{Last glacial maximum}

The last glacial maximum (LGM), approximately 21 kyr BP, provides an opportunity to investigate the impacts of changes in ice-sheet and continent extent on paleomonsoon variability (Kageyama et al. 2018). During the LGM, the reduction of summer monsoon precipitation in the Northern Hemisphere was twice as large as in the Southern Hemisphere. This asymmetric response is mainly caused by the moisture convergence feedback induced by the continental ice-sheet forcing rather than the reduction of moisture content (Cao et al. 2019). The multi-model ensemble mean results suggest that the lowered sea level may lead to expanded land area and thus an enhanced land-sea thermal contrast; this can further lead to a strengthened Australian summer monsoon in contrary to the weakened global monsoon during the LGM (Yan et al. 2018).

\section{Mid-Pliocene}

Generally, a robust enhancement of the West African, Indian, and East Asian summer monsoons was found during the mid-Pliocene (MP), approximately 3.2 million years ago, relative to the $\mathrm{Pl}$, consistent with geological reconstructions (Haywood et al. 2021). When the 11 model simulations are compared with geological records, a northwestward shift in the EASM's northern edge is captured, which is influenced by the intensification and westward extension of western Pacific subtropical high (Huang et al. 2019). Berntell et al. (2021) found that the multi-model ensemble mean in PlioMIP2 simulations shows a significant strengthening of the West African monsoon during the MP, with increased precipitation over the Sahel and Southern Sahara associated with the deepening of the Sahara Heat Low induced by GHG forcing.

\section{Remaining controversial issues} and potential directions

The progress made during PMIP4 discussed above has largely improved our understanding of paleomonsoon variability and the relevant physical mechanisms on various timescales. However, many specific issues remain poorly understood and could benefit from developments of the paleomonsoon modeling and model-data comparisons and syntheses, such as the relative influences of the polar ice-sheet development and the oceanic warm pool on global monsoon variability, further reduction of uncertainty for proxies already in use, and the development of new types of proxies that could identify certain features of the monsoon more accurately (Wang et al. 2017).

Such questions have motivated climatologists around the world and have given rise to strong collaborations between the paleoclimate reconstruction and modeling communities on future studies, on aspects of comparisons, synthesis, and fusion between proxy reconstructions and modeling simulations, through applications of isotope-enabled paleoclimate modeling and paleoclimate data assimilation, as well as other topics. Meanwhile, the paleomonsoon modeling community could also progress further with the help from the developments of the new generation of Earth system models, such as higher-resolution models and improved physical parameterizations, as well as incorporation of new findings from the paleomonsoon reconstruction communities, such as improved reconstructions of external forcings.

\section{AFFILIATION}

School of Geography, Nanjing Normal University, China

\section{CONTACT}

Jian Liu: jliu@njnu.edu.cn

\section{REFERENCES}

Bader J et al. (2020) Nat Commun 11: 4726 Berntell E et al. (2021) Clim Past 17: 1777-1794 Braconnot P et al. (2019) Geophys Res Lett 46: $14,021-14,029$

Brierley C et al. (2020) Clim Past 16: 1847-1872 Cao J et al. (2019) J Clim 32: 6589-6605

Crétat J et al. (2020) Clim Dyn 55: 2761-2784 Haywood AM et al. (2021) Clim Past 16: 2095-2123 Huang X et al. (2019) J Geophys Res Atmos 124: 1392-1404

Jungclaus JH et al. (2017) Geosci Model Dev 10: 4005-4033

Kageyama M et al. (2018) Geosci Model Dev 11: 1033-1057

Otto-Bliesner BL et al. (2017) Geosci Model Dev 10: 3979-4003

Otto-Bliesner BL et al. (2021) Clim Past 17: 63-94 Qin Y et al. (2020) Int J Climatol 40: 5188-5207 Wang PX et al. (2017) Earth-Sci Rev 174: 84-121 Yan M et al. (2018) Clim Past 14: 2037-2052 